\title{
Reeleição Municipal e Performance como Prefeito: Educação e Saúde como Determinantes do Sucesso Eleitoral
}

Municipal Reelection and Performance as Mayor: Education and Health as Determinants of Electoral Success

\author{
Pablo Urano de Carvalho Castelar ${ }^{\mathrm{a}}$ \\ Vitor Borges Monteiro ${ }^{b}$ \\ Paulo de Melo Jorge Netoc
}

\begin{abstract}
Resumo: O artigo analisa o impacto do provimento de serviços públicos na probabilidade de sucesso de candidatos à reeeleição a prefeito nas eleições municipais de 2008. Através de modelo logit com threshold, avalia-se o impacto de variáveis de educação e saúde em reconduzir o atual gestor à reeleição, assim como do gasto em campanha e alinhamento partidário. Os resultados indicam diferença no impacto das variáveis: em municípios acima do threshold, há relação positiva apenas nos índices de educação. Para municípios abaixo, há relação positiva dos índices de saúde e gasto em campanha. Alinhamento partidário mostrouse insignificante.
\end{abstract}

Palavras-chave: Sucesso Eleitoral; Reeleição; Modelo Logit; Educação; Saúde.

Classificação JEL: $\mathrm{D}_{72}, \mathrm{H}_{51}, \mathrm{H}_{52}$

\begin{abstract}
This work analyzes the impact of the provision of public services on the probability of success of reelection candidates for mayor in the 2008 municipal elections. Using a logit model with threshold, the impact of health and education variables is evaluated in choosing the incumbent for reelection, as well as campaign spending and party alignment. The results indicate a difference in the impact of the variables: in municipalities above the threshold, only education has a positive impact. For municipalities below, health services and campaign spending have a positive impact. Party alignment was insignificant.
\end{abstract}

Keywords: Electoral Success; Reelection; Logit Model; Education; Health.

\footnotetext{
a Professor do Curso de Finanças (UFC). E-mail: pcastelar@ufc.br.

b Professor do Curso de Finanças (UFC). E-mail: vitorborges@ufc.br.

c Professor do Departamento de Economia Aplicada e do Programa de Pós-Graduação em Economia CAEN (UFC). E-mail: pjneto@caen.ufc.br.
} 


\section{Introdução}

O debate sobre eleições tem sido frequente e controverso. Na maior parte do mundo, o governo é formado por representantes escolhidos de forma democrática pela sociedade, e com isso bens e serviços públicos requeridos pela população são organizados e fornecidos pelo poder público organizado por esses representantes. Particularmente, no caso brasileiro, surge a importância dos políticos no âmbito executivo, na organização e no provimento de essenciais serviços públicos, como educação e saúde.

Em anos recentes, o enfoque do meio acadêmico tem sido a motivação dos eleitores na escolha desses representantes; ou seja, quais os atributos de um candidato a cargo governamental que são mais valorizados no momento do voto.

Ainda que modelos diversos tenham sido elaborados para explicar a escolha eleitoral numa competição democrática, o cerne da questão permanece sendo em quais plataformas adotadas pelos candidatos são as mais eficientes na captação de votos dos eleitores. As possibilidades são diversas; eleitores podem escolher representantes analisando a sua performance no cargo quando são fornecidos bens e serviços públicos, favorecendo assim a reeleição de candidatos incumbentes, como também pode ser considerada importante a exposição do candidato, associando assim chances de eleição com os gastos de campanha, até fatores de difícil mensuração, como carisma e proximidade com certa parcela da população.

Em um trabalho que analisa os benefícios da separação dos poderes Executivo e Legislativo e como isso impacta o escopo da accountability em termos políticos, Persson, Roland e Tabellini (1997) argumentam que os objetivos e benefícios da realização de eleições podem ser sumarizados em quatro principais aspectos: (i) eleições agregam e representam as preferências conflitantes dos eleitores; (ii) eleições agregam informações dispersas sobre decisões políticas corretas; (iii) eleições tratam de uma questão de seleção adversa, permitindo aos eleitores selecionarem os indivíduos mais competentes para cargos públicos; e (iv) fornecem um mecanismo para controlar o moral hazard, trazendo accountability ao ambiente político.

O presente trabalho toma essa argumentação como motivação para analisar o cenário municipal brasileiro, particularmente focando na questão da accountability no cenário eleitoral, ou seja: a atuação do prefeito que busca reeleição, em especial com relação a sua competência em fornecer bens e serviços públicos, afeta de maneiras diferentes eleitores de localidades com características diferentes?

Esses aspectos estão ligados a um grupo de autores, como Wittman (1989) e Ferejohn (1986), que propuseram que o "mercado político", assim como o 
econômico, é eficiente, e a competição, a regulação e o monitoramento reduzem o comportamento oportunista por parte dos políticos candidatos.

No entanto, uma crítica constante a esses modelos tem sido a questão da informação. Os benefícios para o eleitor se informar seriam menores do que o custo de obter essa informação, já que um voto afetaria relativamente pouco no resultado da eleição, mas buscar se informar sobre um político pode consumir tempo e recursos. Porém, se por um lado os próprios políticos têm interesse em fornecer mais informações aos eleitores, elevando seus gastos de campanha, o próprio monitoramento do sistema público, divulgado de forma abrangente pelo governo e pela mídia, serve de uma base fundamental de informação para a população.

Com isso, diversos autores têm se dedicado a contribuir para o debate não apenas sobre o papel das eleições na economia, mas como os candidatos são escolhidos pelos eleitores e quais aspectos são levados em consideração no momento de votar. Trabalhos como os de Erikson e Wright (2001) e Abramowitz et al. (2006) demonstram de forma convincente que, de fato, candidatos incumbentes têm vantagens sobre os demais em eleições.

Um dos aspectos propostos pela literatura é como o eleitor avalia aqueles que são responsáveis pelo fornecimento de bens e serviços públicos, como educação e saúde. Como relembra Dos Santos (2012), após a promulgação da Emenda Constitucional no 16, em 1997, que permite a reeleição imediata para mais um mandato consecutivo de quatro anos ininterruptos, o eleitor brasileiro compareceu às urnas em quatro ocasiões para eleger seus governadores e presidentes, e em outras três para escolher os prefeitos.

A autora apresenta então a surpreendente taxa de sucesso daqueles prefeitos que decidiram se candidatar à sucessão nas capitais brasileiras; nas eleições municipais de 2000 , vinte e três prefeitos de capitais se recandidataram, sendo que destes, dezesseis foram reconduzidos ao cargo, enquanto que nas eleições de 2004, onze prefeitos concorreram à reeleição, e oito obtiveram êxito. Já nas eleições municipais de 2008 , há considerável sucesso por parte dos candidatos já no poder, em que dezenove prefeitos foram reconduzidos ao cargo, do total de vinte que concorriam à reeleição. Barreto (2010 apud DOS SANTOS, 2012) analisou 62 municípios brasileiros, no período compreendido entre 2000 e 2008, sendo 26 capitais e 36 municípios que contavam com 200 mil eleitores. $O$ autor concluiu que $72,5 \%$ dentre aqueles que tentaram a reeleição, obtiveram sucesso.

Berry e Howell (2007) argumentam que, de fato, a vantagem dos incumbentes em uma eleição está atrelada ao desempenho desses na administração pública. Analisando a questão da chamada votação retrospectiva, no qual fatores econômicos afetam os prospectos eleitorais dos candidatos que buscam a reeleição, os autores associam votos para membros de diretorias do setor educacional com a performance das escolas. 
O presente trabalho almeja, então, averiguar o impacto na probabilidade de eleição de candidatos a prefeito que já se encontram no cargo considerando a percepção dos eleitores sobre índices relacionados a serviços públicos, como educação e saúde, especificamente uma melhor qualidade nas escolas, observando os dados do IDEB, divulgados poucos meses antes das eleições municipais de 2008, e também a quantidade de atendimentos ambulatoriais, uma proxy para a qualidade do sistema de saúde público. No caso, a amostra é reduzida para abranger apenas os candidatos aptos à reeleição nas eleições em questão, já que é necessário observar a performance do candidato que estava no poder gerindo o sistema de ensino municipal e de saúde.

Ressalta-se, assim, uma hipótese contundente adotada: municípios de renda per capita mais elevada possuem mais eleitores "ideológicos", i.e., que buscam com mais afinco informações a respeito da atuação de um político, e municípios de menor renda per capita possui, por outro lado, menos eleitores "ideológicos", onde o custo pela busca de informação seria mais elevado.

Logo, assim como em Firpo et al. (2012), o trabalho aqui proposto deriva do arcabouço teórico apresentado em Persson, Roland e Tabellini (1997), no qual um modelo de agência política contém eleitores que votam utilizando informação imperfeita sobre o atual prefeito e sua gestão, relacionando os resultados divulgados sobre desempenho educacional, no caso a nota do exame IDEB, como ferramenta de avaliação por parte dos eleitores. Considerando que as escolas de ensino fundamental do município são responsabilidade dos prefeitos, conforme determinado no Artigo 211 da Constituição', possivelmente a observação de melhorias no ensino seria considerada pela população como motivo para manter um prefeito no cargo.

No entanto, no presente artigo, diferenciamos a análise da proposta no trabalho supracitado ao incluir, além da questão educacional, outro importante serviço público: o atendimento no serviço de saúde municipal. Novaes e Mattos (2010), por exemplo, em análise do efeito da intenção de reeleição sobre os gastos em saúde a nível municipal no Brasil, argumentam que prefeitos candidatos à reeleição agem estrategicamente para convencer o eleitorado à recondução, fazendo um esforço, através de maiores gastos em saúde, para mostrar aos seus eleitores que são administradores competentes.

Para tanto, pretende-se realizar a observação dessa variável através da quantidade de atendimentos no sistema do SUS sob responsabilidade do prefeito. Ainda que a quantidade de atendimentos não leve em consideração a qualidade do serviço, pressupõe-se que a população considera mais relevante ser atendida, e

\footnotetext{
${ }^{1}$ Emenda Constitucional no 14/96 inseriu a expressão "educação infantil”, modificando a redação anterior que mencionava apenas a educação pré-escolar (de Sena, 2004).
} 
responsabiliza o prefeito pela capacidade das unidades de saúde. Diversas pesquisas ${ }^{2}$ destacam a insatisfação do usuário do sistema de saúde brasileiro, sendo algumas das principais reclamações o tempo de fila de espera e a falta de atendimento. Já um atendimento inadequado pode ter interpretação difusa por parte do paciente/eleitor, podendo responsabilizar tanto o profissional, os dirigentes do hospital quanto o próprio governante 3 .

A alternativa seria utilizar gastos em saúde pública. No entanto, haveria a dificuldade de contabilizar a questão do gasto ineficiente, que não necessariamente se traduz em qualidade.

Certamente, o que pode ser questionado de forma mais veemente é o poder de observação, por parte da população, sobre o quesito educação. Contudo, a hipótese a ser trabalhada é justamente a que níveis de renda per capita em termos de diferentes municípios a qualidade na educação passa a ser considerada no momento da eleição. De início, especula-se que populações de municípios mais ricos, onde há maiores eleitores informados (ideológicos), considerariam de suma importância a gestão do sistema educacional por parte de um prefeito. Por outro lado, talvez populações mais carentes estejam mais atentas à simples presença do candidato na mídia, associando gastos em campanha ou o fato do candidato estar apto à reeleição a uma maior possibilidade de eleição. Para isso, a metodologia threshold é utilizada, visando um nível de renda que permita inferir se há de fato uma divisão na avaliação de eleitores de municípios com características diferentes.

Este trabalho está disposto da seguinte maneira: além desta introdução, é feito um breve resumo da literatura acadêmica disponível sobre o tema. Depois, uma discussão sobre sistemas de avaliação de ensino, com foco no IDEB, e também sobre Economia da Saúde no Brasil. Posteriormente, a estatística descritiva é debatida, sendo apresentados os dados, e expõe-se o modelo de Persson, Roland e Tabellini (1997), que motiva o trabalho. Apresenta-se, então, o modelo logit com treshold, adotado como metodologia. Finalmente, os resultados são discutidos, assim como as conclusões do artigo.

\section{Revisão de Literatura}

Hanushek (2005) afirma que há evidência de que a qualidade das escolas tem relação forte com efeitos econômicos. No entanto, o autor alerta para o fato de

\footnotetext{
${ }^{2}$ Ver, por exemplo, a pesquisa realizada pelo Conselho Federal de Medicina "Opinião dos Brasileiros Sobre o Atendimento na Ârea de Saúde”. Disponível em:

http://portal.cfm.org.br/images/PDF/apresentao-integra-datafolha203.pdf. Acesso: 10/o4/2019.

3 Para uma discussão a respeito da responsabilização no sistema de saúde, ver Gomes (2010).
} 
que melhorar a qualidade da educação é difícil, algo que leva tempo, e que não está necessariamente relacionado de forma direta com os níveis de dispêndio na área.

Diversos trabalhos, como o de Topel (1999) e Krueger e Lindahl (2001), a nível internacional, e Mendes (2013) a nível nacional, apresentam a relação entre a quantidade de anos de estudo e aumento na produtividade individual e/ou crescimento nacional. Ainda que haja um impacto positivo, e a maioria dos estudos aponta nessa direção, da quantidade de estudo na produtividade e crescimento econômico, a qualidade do ensino nem sempre é observável de forma mais direta pelos eleitores, e é possivelmente um instrumento importante para avaliar seus candidatos conforme essa qualidade muda no curto prazo.

A importância da qualidade da escola, para Hanushek (2005), é que maiores índices de qualidade também levariam a um aumento no produto nacional - o que pode fazer com que esse gasto maior em educação no presente seja financiado no futuro pelo crescimento da economia. Alguns trabalhos, como Mulligan (1999) e Lazear (2001, 2003) apresentam, por exemplo, resultados que sugerem uma relação entre o desempenho dos alunos em provas na escola com os salários recebidos no mercado de trabalho.

Os trabalhos supracitados estipulam que uma proxy apropriada para qualidade escolar é a performance dos estudantes em testes padronizados, como é o caso do IDEB, cujos resultados são utilizados neste trabalho.

Para que haja a possibilidade de avaliar a observação, por parte da população, do desempenho do prefeito, especificamente sobre sua gerência do ensino público, naturalmente apenas candidatos no poder devem fazer parte da amostra. A questão da reeleição e de como a possibilidade desta impacta nas chances do candidato, além de outros aspectos relacionados ao aumento de probabilidade de eleição daqueles políticos já no cargo tem sido debatido, também, por diversos autores.

No âmbito nacional, em trabalho próximo do aqui proposto, Firpo et al. (2012) analisam a questão de accountability com foco específico na qualidade do ensino, estudando como os resultados do IDEB tiveram impacto nas eleições municipais de 2008. Através do método de diferenças em diferenças, utilizando os resultados das eleições de 2004 (antes do IDEB) e 2008 (pós-IDEB), as conclusões do trabalho apontam que, em média, um acréscimo de um ponto no IDEB entre 20052007 aumentou cerca de 4,5 pontos percentuais a probabilidade de reeleição, e esses resultados são ainda mais contundentes nos casos de municípios onde, proporcionalmente, há maior quantidade de matrículas em educação básica, há maior demanda, por conta da demografia municipal, por educação básica, e há uma quantidade maior de famílias carentes cuja única opção é o ensino público.

Mendes e Rocha (2004), em trabalho que analisa as eleições municipais do ano 2000, indagam sobre quais fatores determinam de forma contundente a 
probabilidade de reeleição de um prefeito. Uma gestão vista de forma positiva, o envolvimento ou não em atos irregulares, os projetos apresentados, a questão fiscal, todos esses aspectos são considerados. Um resultado importante é de que os eleitores consideram a atuação do prefeito de forma apenas parcial, dando mais importância aos fatos noticiados com destaque na imprensa. Maior gasto público também aumenta a probabilidade de reeleição, sugerindo que a disciplina fiscal não é favorecida no caso de prefeitos já no cargo que pretendem se manter no poder.

Cançado e Araújo Jr. (2004) analisam a questão da eleição no âmbito das eleições municipais de Minas Gerais também do ano 200o. Assim como o trabalho aqui proposto, esse artigo utiliza um modelo logístico de regressão para observar a reeleição como variável dependente, e quais variáveis modificam a probabilidade de reeleição dos prefeitos. Os resultados que os autores apresentam sugerem que a probabilidade de reeleição diminui à medida que o gasto público aumenta, enquanto que a probabilidade aumenta quando a receita do município está crescendo. Ser do partido do Presidente e do Governador também aumentam as chances de reeleição.

Sakurai e Menezes Filho (2008) analisam as eleições municipais de 1988 a 2000 no Brasil utilizando um modelo logit de efeitos fixos. O objetivo do trabalho é examinar como a probabilidade de reeleição dos prefeitos é afetada pelos gastos municipais em anos em que ocorrem eleições e anos em que essas não ocorrem. Naturalmente a hipótese a ser testada é se ocorre manipulação fiscal visando a reeleição, e se de fato um aumento de gastos propicia maior probabilidade de se manter no poder. Os resultados obtidos dos exercícios econométricos sugerem que gastos mais elevados durante um período no cargo aumentam a probabilidade do político de permanecer no cargo depois de um novo pleito.

Os autores também concluem que maiores gastos em capital nos três anos que precedem a eleição e mudanças nos gastos no ano eleitoral quando comparados aos anos anteriores também beneficiam o candidato que já está no poder. Dois outros resultados curiosos do trabalho são de que o candidato estar alinhado com o Presidente da República implica em perda de popularidade para o candidato à reeleição como prefeito, o que pode estar ligado a crises macroeconômicas vigentes no período analisado, e há uma heterogeneidade relativa entre os partidos políticos brasileiros em relação às suas probabilidades inerentes de sucesso eleitoral, o que pode estar relacionado às diferentes preferências dos brasileiros em relação a esses grupos políticos e suas gestões.

Outro trabalho próximo a este é o de Klein (2010), que testa a presença do Political Business Cycle (PBC) nas eleições municipais brasileiras de 2004, observando se os políticos que adotaram tal método de aumento de gastos públicos tiveram maior probabilidade de reeleição. Utilizando os métodos econométricos de diferenças-em-diferenças e regressão logística, o autor mostra que, na média, 
prefeitos buscando reeleição gastam $5 \%$ a mais no orçamento do que prefeitos nãoreelegíveis e não concorrentes.

Meloni (2011) também associa reeleição aos ciclos políticos, e sua investigação almeja averiguar se políticos enfrentam um trade-off em anos de eleição quando decidem realizar ciclos da política econômica em anos eleitorais. A ideia é que, se por um lado, a realização dos ciclos pode refletir em aumento da probabilidade de reeleição, por outro lado é razoável supor que o político incorre em algum tipo de custo ao realizar esses ciclos.

Para isso, o autor utiliza uma proxy para medir a expectativa do candidato incumbente tem de ser reeleito, que é o resultado do partido nas eleições para governador do estado aonde se encontra o município em que o candidato é prefeito. Os resultados indicam que os políticos tendem a aumentar os gastos com transferências em anos eleitorais, e esses recursos advêm de uma redução nos gastos correntes (por exemplo, com pessoal). Os resultados mostram também que, à medida que a probabilidade de reeleição aumenta, esse movimento do ciclo político tende a se reverter, ou seja, quanto maior a expectativa do prefeito em se reeleger, menos ele distorce os gastos em favor de transferências correntes em anos eleitorais, dando margem à interpretação de que o custo político de tais distorções pode ser considerável e um risco a ser evitado, quando possível.

Ainda sobre ciclos políticos eleitorais e gastos públicos, Videira e Mattos (2011) analisam a teoria de ciclos políticos eleitorais para estudar o comportamento dos gastos no momento das eleições entre o período de 1997 e 2008 para os municípios brasileiros, com foco na interação espacial entre esses municípios. Ao longo das estimações do trabalho, os autores encontram que a variável política apresenta coeficiente positivo para os gastos com investimentos, educação e saúde, o que denota o fato de que, em ano eleitoral, tais despesas sofrem aumento com o objetivo de sinalizar competência por parte do incumbente. Assim, segundo os autores, a hipótese principal do artigo é corroborada, pois além da evidência de interação espacial nos gastos dos municípios de forma direta, em ano eleitoral, o padrão dos gastos dos municípios vizinhos altera o comportamento da variável de investimentos (e de educação) no ano eleitoral dos municípios em questão, fazendo com que a resposta destes em anos eleitorais seja positiva.

Novaes e Mattos (2010) analisam especificamente a relação entre intenção de reeleição e gastos em saúde, utilizando um modelo de reputação com base naquele proposto por Besley e Case (1995 apud NOVAES; MATTOS, 2010). A variável dependente, no caso, é o log do gasto municipal em saúde per capita, e são incluídas no modelo variáveis eleitorais, que descrevem a situação do político, se está no primeiro ou segundo mandato, se está apto à reeleição, se foi precedido por um colega de partido, além de vetores de controle para elementos como relação com partido do governador e presidente, controles de saúde e aspectos do município 
como população, acesso à água encanada e a saneamento básico etc. A eleição investigada é a de 2004, e os autores utilizam diversas especificações econométricas, como Pooled OLS, painel de efeito aleatório, efeito fixo e primeira diferença.

Os resultados sugerem que prefeitos candidatos à reeleição agem estrategicamente para convencer o eleitorado a restituí-los ao cargo. Por sua vez, prefeitos em segundo mandato não aumentam as despesas quando encaram o final de seu mandato. Ou seja, o modelo de reputação se encaixa aos municípios brasileiros: prefeitos que tentam reeleição se esforçam, através de maiores gastos em saúde, para mostrar aos seus eleitores que são administradores competentes, ao contrário de prefeitos em segundo mandato.

Os autores encontram ainda que incentivos partidários têm influência na administração municipal, onde o modelo de reputação omite qualquer efeito da eleição subsequente ao prefeito que não tenta ou não pode se reeleger. Porém, os resultados sugerem que importa ao prefeito que seu sucessor seja de seu partido.

\section{Educação e Saúde}

\subsection{Um breve histórico sobre o IDEB}

Primeiramente, deve-se apresentar como a avaliação de alunos e escolas é realizada. O Índice de Desenvolvimento de Educação Básica (IDEB) foi criado em 2007, com o intuito de medir a qualidade da educação no país, numa escala de o a 10. A partir desse instrumento, o Ministério da Educação traçou metas de desempenho bianuais para cada escola e cada rede até 2022; o índice é, então, medido a cada dois anos e o objetivo é que o país, a partir das metas municipais e estaduais, tenha nota 6 em 2022.

Portanto, com o IDEB, os sistemas municipais, estaduais e federais de ensino têm metas de qualidade para atingir. O índice é elaborado pelo Instituto Nacional de Estudos e Pesquisas Educacionais Anísio Teixeria (INEP/MEC), e é calculado com base no desempenho do estudante em avaliações do INEP e em taxas de aprovação. O índice se inicia considerando também as notas do sistema anterior, em 2005, fazendo-se uma ponderação das avaliações realizadas pela Prova Brasil.

Os primeiros resultados do IDEB foram divulgados pouco antes das eleições municipais de 20084 , ou seja, os eleitores já conheciam as notas das escolas dos municípios, tanto para 2005, quanto 2007. Neste trabalho, é feito uma média das notas desses dois momentos anteriores às eleições, considerando as notas de alunos do $4^{\circ}$ e $5^{\circ}$ ano do ensino fundamental.

\footnotetext{
4 http://www1.folha.uol.com.br/folha/educacao/ult305u41159o.shtml. Acesso em: 10/o4/2019.
} 
O motivo para a utilização apenas da $4^{\underline{a}}$ e $5^{\underline{a}}$ série é de que a grande maioria dos municípios oferecem estas séries em suas escolas municipais; no entanto, um número consideravelmente reduzido de municípios possui escolas com $8^{\underline{a}}$ e $9^{\underline{a}}$ série, que também são avaliadas pelo IDEB.

Em trabalho que analisa sistemas de avaliação e indicadoras da qualidade de educação, Fernandes e Gremaud (2009) apresentam o histórico recente das tentativas do governo brasileiro de implantar maior eficiência nas escolas.

O Plano de Desenvolvimento da Educação, lançado pelo MEC em 2007, tem algumas inovações importantes, como a incorporação dos objetivos de accountability (que supostamente eleva o desempenho dos estudantes), a criação de um indicador sintético da qualidade da educação básica, que considera simultaneamente o desempenho dos alunos em exames padronizados e a progressão dos alunos no sistema, e a definição de metas para o país e para cada sistema e escola em particular.

Ainda de acordo com Fernandes e Gremaud (2009), o principal marco da avaliação da educação no Brasil é o Sistema de Avaliação da Educação Básica (SAEB), que tem início ainda na década de 8o. No entanto, o programa apresenta defeitos, por ter caráter amostral e não apresentar a diversidade educacional no país. Com isso, a Prova Brasil é implantada em 2005, sendo censitária, focando em alunos das $4^{\underline{a}}$ e $8^{\text {a }}$ série (respectivamente, $5^{\circ}$ e $9^{\circ}$ ano) de escolas públicas e urbanas de ensino fundamental.

No ano de 2007, novamente o Ministério da Educação busca uma nova metodologia de avaliação do ensino, e com isso a Prova Brasil e SAEB são fundidos para criar o IDEB. Como apresenta Fernandes e Gremaud (2009), programas de accountability possuem o potencial para elevar o desempenho de estudantes, mas apresentam riscos. No Brasil, um dos principais riscos de um programa baseado apenas em exames padronizados é o de contribuir para o quadro de repetência e evasão escolar. Com o IDEB, surge a ideia de criar um indicador de educação básica que, tanto para efeitos de monitoramento, quanto para fins de accountability, combinasse a informação de desempenho em exames com informação sobre o fluxo escolar.

O IDEB é resultado, então, da combinação da pontuação média dos estudantes em exames padronizados ao final de uma determinada etapa da educação básica e a taxa média de aprovação dos estudantes da correspondente etapa de ensino.

$$
\text { IDEB }=N^{*} B \text {, }
$$

onde: $\mathrm{N}$ = proficiência média dos alunos e $\mathrm{B}=$ taxa média de aprovação. 
A média de proficiência combina as notas de matemática e português e a proficiência média é padronizada para estar entre o e 10, enquanto a taxa de aprovação se situa entre o e 1, assim o IDEB fica entre o e 10.

\subsection{O Sistema de Saúde no Brasil}

A saúde é um ponto crítico entre os serviços públicos prestados à população. Ainda que a educação seja de suma importância, seu impacto no bemestar social é nitidamente de longo prazo, onde há um hiato entre o custo econômico e seus eventuais benefícios, tendo em vista que o processo de aprendizagem e formação é demorado, durando vários anos. A saúde tem perfil imediatista, em que a maior parte da população brasileira depende exclusivamente do sistema público para ações de prevenção, acompanhamento, intervenção e recuperação.

Segundo Forns (1998 apud SAES, 200o), em análise sobre o âmbito da economia na saúde, argumenta que a economia, enquanto disciplina social, se ocupa da saúde e dos fenômenos sociais desde uma perspectiva comunitária, tal como se faz na saúde pública.

Dessa forma, além da importância já discutida da educação, a saúde é dos serviços públicos fundamentais fornecidos pelo governante, o que leva à natural suposição de que os eleitores observam o atendimento nas diversas unidades de saúde, especificamente aquelas com profissionais ligados ao município, para avaliar a gestão de um governante.

O Sistema Único de Saúde - SUS - foi criado pela Constituição Federal de 1988 e regulamentado pelas Leis no 8080/9o e no 8.142/90, Leis Orgânicas da Saúde, com a finalidade de alterar a situação de desigualdade na assistência à Saúde da população, tornando obrigatório o atendimento público a qualquer cidadão, sendo proibidas cobranças de dinheiro sob qualquer pretexto. A União é o principal financiador da saúde pública no país. Historicamente, metade dos gastos é feita pelo governo federal, a outra metade fica por conta dos estados e municípios. A União formula políticas nacionais, mas a realização é feita por seus parceiros (estados, municípios, ONGs e iniciativa privada) ${ }^{5}$.

Conforme exposto na Cartilha do Sistema Único de Saúde fornecido pelo Governo Federal, a partir de 2006, com o chamado Pacto Pela Saúde, o gestor municipal assina um termo de compromisso para assumir integralmente as ações e serviços no âmbito da saúde. O município, assim, formula suas políticas de saúde,

\footnotetext{
${ }^{5}$ Entendendo o SUS: Cartilha do Ministério da Saúde, 2006, Disponível em: http://portal.saude.gov.br/portal/arquivos/pdf/cartilha_entendendo_o_sus_2007.pdf. Acesso: 10/04/2019.
} 
formando parcerias com o Governo Federal na aplicação de políticas nacionais, coordenando e planejando o SUS a nível municipal.

A proxy utilizada para compor a variável que identifica a qualidade da saúde é a rubrica procedimentos ambulatórios, que são todos aqueles procedimentos realizados que não necessitam de internação, como aplicação de vacina, partos, testes e coleta de material, diversos procedimentos cirúrgicos, drenagens, biópsias, atendimento a queimados, procedimentos odontológicos etc.

Um interessante estudo a respeito da busca por serviços de saúde, incluindo-se aí o SUS, é o de Porto et al. (2011), que, utilizando dados da Pesquisa Nacional por Amostra de Domicilio (PNAD), analisa a evolução do perfil das pessoas que utilizaram tais serviços entre 2003 e 2008 no Brasil.

Como sumarizado por Ruiz (2012) $)^{6}$, os pesquisadores não encontram diferenças significantes entre 2003 e 2008 no perfil sociodemográfico das pessoas que procuraram atendimento em serviços de saúde: existe maior procura de serviços por mulheres ( $17 \%$ contra $12 \%$ dos homens); aumenta a procura por serviços em função da idade (12\% em o-14 anos para $23 \%$ acima dos 60 anos); e nos extremos de escolaridade também se eleva quando aumenta a renda familiar per capita.

Nos motivos referentes à procura do serviço, também não houve diferença: mais de 50\% dos entrevistados alegaram motivo de doença tanto em 2003 quanto em 2008; atividades de prevenção como pré-natal, vacinação e outros, constituíram o segundo motivo mais frequente de procura de serviços, observando-se um declínio na proporção (31,3\% em 2003 contra $24,7 \%$ em 2008). O SUS foi responsável pelo atendimento de $58,5 \%$ dos entrevistados em 2003 e por $56,7 \%$ em 2008.

Esses dados sobre os motivos de busca por serviços de saúde parecem validar a utilização de procedimentos ambulatoriais como uma boa proxy para a qualidade do sistema de saúde no município.

\section{A Base de Dados e Estatística Descritiva}

A eleição municipal de 2008 foi escolhida como foco de estudo deste trabalho. Todos os municípios brasileiros são incluídos na amostra. Como foi exposto, apenas os candidatos aptos à reeleição foram escolhidos, de forma a analisar apenas aqueles que já estavam no poder e tinham uma gestão a ser observada pela população. Os dados referentes aos candidatos foram colhidos junto ao Tribunal Superior Eleitoral - TSE. No entanto, para corrigir um possível viés de seleção,

\footnotetext{
${ }^{6}$ Disponível em: http://dssbr.org/site/2012/o4/quem-usa-o-sistema-unico-de-saude-2/. Acesso: 10/04/2019.
} 
também foram utilizados dados das eleições de 2000, 2004 e 2006 para formular a equação de seleção amostral.

Tabela 1: Organização da seleção amostral

\begin{tabular}{c|c|c|c}
\hline \hline $\begin{array}{c}\text { Prefeitos Eleitos } \\
\text { em 2004 }\end{array}$ & $\begin{array}{c}\text { Reeleitos em } \\
\mathbf{2 0 0 4}\end{array}$ & $\begin{array}{c}\text { Candidatos em } \\
\mathbf{2 0 0 8}\end{array}$ & Reeleitos em 2008 \\
\hline \multirow{2}{*}{5562} & Sim $=1001$ & & Sim $=1961$ \\
\cline { 2 - 4 } & \multirow{2}{*}{ Não $=4561$} & Sim $=2845$ & Não $=884$ \\
\cline { 2 - 4 } & & Não $=\mathbf{2 7 1 7}$ & \\
\hline \hline
\end{tabular}

Fonte: Elaboração dos autores.

Tabela 2: Média de Gastos em Campanha e IDEB

\begin{tabular}{|c|c|c|c|c|c|}
\hline \multicolumn{3}{|c|}{ Sucesso Eleitoral } & \multirow{2}{*}{$\begin{array}{l}\text { Média de } \\
\text { gastos } \\
\text { em } \\
\text { campanha }\end{array}$} & \multirow[b]{2}{*}{$\begin{array}{l}\text { Média } \\
\text { IDEB }\end{array}$} & \multirow{2}{*}{$\begin{array}{c}\text { Média de } \\
\text { quantidade de } \\
\text { atendimentos } \\
\text { (Saúde) }\end{array}$} \\
\hline Valor & $\begin{array}{l}\text { Quant. de } \\
\text { Candidatos }\end{array}$ & Perc. \% & & & \\
\hline 1 & 1961 & $68,93 \%$ & 26.689 & 3,38 & $33 \cdot 519,28$ \\
\hline o & 884 & $31,07 \%$ & 20.084 & 3,34 & $22.950,93$ \\
\hline Total & 2845 & $100,00 \%$ & 23.386 & 3,37 & $30.235,48$ \\
\hline
\end{tabular}

Fonte: Elaboração dos autores.

Na Tabela 2, está exposta a quantidade de candidatos que estavam aptos à reeleição na amostra, 2.845. Destes, 1.961 (67,24\%) obtiveram êxito e foram reconduzidos ao cargo nos seus respectivos municípios. A média de gastos dos reeleitos foi de $\mathrm{R} \$ 125.074,89$, consideravelmente maior do que a média dos que não tiveram sucesso, R\$ 85.109,87. A média do IDEB, exame que indica a qualidade das escolas, foi de 3,38 nos municípios dos prefeitos reeleitos, e 3,34 nos municípios que não tiveram seus prefeitos reeleitos.

Observa-se também a média de atendimentos no sistema de saúde pública, ligado à gestão municipal. Nos municípios com prefeitos reeleitos, a média de atendimentos, nos 12 meses que antecederam as eleições de outubro 2008 , foi de 33.519,28 atendimentos. Nos municípios onde os prefeitos não conseguiram a reeleição, a quantidade de atendimentos foi, em média, de 22.950,93 no mesmo período.

Finalmente, são incluídas, na forma de variáveis binárias, a condição do candidato em relação a fazer parte ou não da coligação do Governador do Estado ao qual pertence o município, e a coligação do Presidente da República, e esses dados também foram obtidos junto ao TSE. Vale ressaltar que no modelo principal, 
considera-se a legenda do candidato em 2008, enquanto na equação de seleção, a legenda do mesmo em 2004. Porém, ambos como referência às eleições de Governador e Presidente de 2006.

Tabela 3: Partido do Governador, Gastos, IDEB e Saúde

\begin{tabular}{|c|c|c|c|c|c|}
\hline \multicolumn{3}{|c|}{ Partido do Governador } & \multirow{2}{*}{$\begin{array}{l}\text { Média de gastos } \\
\text { em campanha }\end{array}$} & \multicolumn{2}{|c|}{$\begin{array}{c}\text { Médias de IDEB e } \\
\text { Saúde }\end{array}$} \\
\hline Valor & obs & Perc. \% & & IDEB & Saúde \\
\hline 1 & 1.535 & $53,96 \%$ & $\mathrm{R} \$ 81.321,16$ & 3,42 & 22.326 \\
\hline $\mathrm{O}$ & 1.310 & $46,04 \%$ & $\mathrm{R} \$ 85.079,67$ & 3,30 & 27.103 \\
\hline Total & 2845 & $100,00 \%$ & $\mathrm{R} \$ 83.200,41$ & 3,36 & 24.714 \\
\hline
\end{tabular}

Fonte: Elaboração dos autores.

Já na Tabela 3, observa-se a variável Partido do Governador, que estabelece se o partido do prefeito candidato à reeleição faz parte ou não da coligação de partidos do Governador do Estado ao qual pertence o seu município. Ao lado, encontram-se a média de gastos em campanha do político, assim como as médias do IDEB e da quantidade de atendimentos no sistema de saúde. 1.535 prefeitos, ou $53,96 \%$ da amostra, pertenciam a partidos que faziam parte da coligação do partido do Governador do Estado, enquanto que 1.310, ou 46,04\%, estavam em situação independente. Nos municípios em que o prefeito estava alinhado com o Governador, a média dos gastos em campanha política foi de $\mathrm{R} \$ 81.321,16$, enquanto a média de gastos daqueles que não faziam parte da coligação partidária foi de 85.079,67, superior aos seus oponentes ligados ao governo do Estado. Quanto ao IDEB, as médias nas prefeituras ligadas à coligação do governador foi de 3.42, enquanto que nos demais, a média foi de 3.30. Por fim, as médias de quantidade de atendimento no sistema de saúde público foi de $\mathbf{2 2 . 3 2 6}$ em prefeituras ligadas ao governador, enquanto que nas prefeituras de candidatos que não faziam parte da coligação, a quantidade foi de 27.103 atendimentos.

Tabela 4: Partido do Presidente, Gastos, IDEB e Saúde

\begin{tabular}{c|r|r|r|r|r}
\hline \hline \multicolumn{3}{c|}{ Partido do Presidente } & \multirow{2}{*}{$\begin{array}{c}\text { Média de gastos } \\
\text { em campanha }\end{array}$} & \multicolumn{2}{c}{$\begin{array}{c}\text { Médias de IDEB e } \\
\text { Saúde }\end{array}$} \\
\cline { 1 - 1 } Valor & \multicolumn{1}{|c|}{ obs } & \multicolumn{1}{c|}{ Perc. \% } & & \multicolumn{1}{c}{ IDEB } & \multicolumn{1}{c}{ Saúde } \\
\hline 1 & 276 & $9,71 \%$ & $\mathrm{R} \$ 136.567,50$ & 3,28 & 34.419 \\
\hline $\mathrm{o}$ & 2.569 & $90,29 \%$ & $\mathrm{R} \$ 77.328,91$ & 3,37 & 23.467 \\
\hline Total & 2845 & $100,00 \%$ & $\mathrm{R} \$ 106.948,20$ & 3,32 & 28.943 \\
\hline \hline
\end{tabular}

Fonte: Elaboração dos autores. 
A Tabela 4 apresenta a variável Partido do Presidente, ou seja, candidatos que faziam parte do partido do então Presidente da República, ou a coligação deste, recebem valor 1 , e no caso contrário, valor o. Nessa tabela, observa-se que prefeitos ligados ao Partido dos Trabalhadores, ou que faziam parte de sua coligação, gastaram, em média, mais do que seus concorrentes. Nessas prefeituras, as escolas apresentaram IDEB inferior, em média, às demais, enquanto que a quantidade de atendimentos ambulatoriais foi superior, em média de 34.419 atendimentos.

Tabela 5: Renda per capita, IDEB e Saúde

\begin{tabular}{|c|c|c|c|c|}
\hline \multicolumn{3}{|c|}{ Renda per capita } & \multirow{2}{*}{$\begin{array}{c}\text { IDEB } \\
\text { Média }\end{array}$} & \multirow{2}{*}{$\begin{array}{l}\text { Saúde } \\
\text { Média }\end{array}$} \\
\hline Valor R\$ & Quant. Municípios & Perc. \% & & \\
\hline$\leq 3.170,00$ & 1.522 & $61,27 \%$ & 2,79 & 14.632 \\
\hline$>3.170,00$ & 1323 & $38,73 \%$ & 3,72 & 30.777 \\
\hline Total & 2485 & $100,00 \%$ & 3.25 & 22.704 \\
\hline
\end{tabular}

Fonte: Elaboração dos autores.

Por fim, a Tabela 5 estabelece a quantidade de municípios que está acima e abaixo do efeito limiar calculado de $\mathrm{R} \$ 3 \cdot 317 \mathrm{O}^{7}$. 1.522 dos municípios, ou $61,27 \%$ da amostra, encontra-se acima do efeito limiar, e 1.323, ou 38,73\%, abaixo. A média do IDEB dos municípios de renda per capita mais elevada foi de 3,72, enquanto que a média nos municípios de renda mais baixa foi de 2,79. Em relação aos atendimentos no sistema de saúde, a média dos municípios mais ricos da amostra foi de 30.777, enquanto que nos municípios mais carentes a média foi de 14.632 .

\section{O Modelo de Persson, Roland e Tabellini (1997)}

O princípio da consideração retroativa, por parte da população, a respeito dos serviços públicos fornecidos pelo governante como aspecto importante para reconduzir esse último ao cargo baseia-se no modelo apresentado no trabalho de Persson, Roland e Tabellini (1997). Nesse artigo, supõe-se um número grande de eleitores idênticos e de vida infinita que maximizam de forma conjunta a seguinte função de utilidade esperada:

$$
E \sum_{t=0}^{\infty} \delta^{t} u\left(c_{t}\right)
$$

7 Optou-se por adiantar o efeito limiar obtido através do modelo logit com o objetivo e enriquecer a análise descritiva dos dados. 
onde: $\mathrm{o}<\delta<1, E$ é a esperança, $u\left(c_{t}\right)$ é a função utilidade côncava monotonicamente crescente em $c_{t}$. A expressão $c_{t}$ representa o consumo de bens públicos dos eleitores, e é definida por:

$$
c_{t}=\theta_{t}\left(1-x_{t}\right)
$$

onde: $\theta_{t}$ é uma variável aleatória não-negativa, não correlacionada serialmente e identicamente distribuída no tempo. Este pode ser considerado como um parâmetro de produtividade que explica como o orçamento é transformado em bens públicos que serão consumidos pela população. A variável $x_{t}$ é definida pelo governante, onde para $x_{t}>0$, o governante está desviando recursos que estariam normalmente beneficiando os eleitores. Caso $x_{t}<0$, o governante adiciona recursos que irão beneficiar os eleitores. Em suma, o que $x_{t}$ capta é o conflito de interesses entre o governo e a sociedade sobre a alocação dos gastos públicos.

Fica implícito em (2) que, com $c_{t} \geq 0$, há uma restrição orçamentária que limita o quanto o governante pode se apropriar em cada período, ou seja, $x_{t} \leq 1$. O governante maximiza então a função utilidade esperada:

$$
E \sum_{t=0}^{\infty} \delta^{t} v\left(x_{t}\right)
$$

onde: $v(0)=0, v_{x}\left(x_{t}\right)>0, v_{x x}\left(x_{t}\right) \leq 0 \forall x_{t}$.

Assim, os candidatos são escolhidos de forma aleatória dentro da população, o $c$ captura o consumo de bens públicos e $\mathrm{o} x$ está mais relacionado ao consumo de bens privados. A lógica do modelo é a seguinte: no começo de cada período $t$, os eleitores escolhem uma regra de votação condicional às informações que possuem no final do período. O parâmetro $\theta_{t}$ é observado pelo governante, que escolhe então uma ação $x\left(\theta_{t}\right)$ conhecendo a regra de votação. No final do período $t$, os eleitores observam $c_{t}$, o provimento dos bens públicos, e dependendo da quantidade de informação disponível, podem também perceber $\theta_{t}$. Baseando-se nessas observações e seguindo a regra de votação, os eleitores reelegem o governante ou não.

O objetivo do presente trabalho, então, é partir do princípio modelado por Persson, Roland e Tabellini (1997), de que os eleitores observam a performance do candidato no poder conforme o provimento de bens e serviços públicos que beneficiam a sua utilidade, no caso a variável $c_{t}$, e que esses políticos determinam a alocação de recursos para o fornecimento desses bens. Para $c_{t}$, são utilizadas proxies para a qualidade da educação e da saúde, respectivamente, a nota do exame IDEB e a quantidade de atendimentos ambulatoriais no sistema público de saúde. 
Utiliza-se o modelo logit para determinar a probabilidade do sucesso eleitoral do candidato que busca a reeleição. Na seção abaixo, faz-se uma breve apresentação dessa metodologia.

\section{Modelo Logit e Efeito Threshold}

\subsection{Modelo Logit}

Um dos objetivos dos modelos de respostas binárias consiste em estimar a probabilidade de um indivíduo com determinado conjunto de atributos (LIMA, 1996). O modelo econométrico logit foi escolhido, pois é adequado a trabalhar com variáveis dependentes de respostas binárias.

Gujarati (2000) afirma que o modelo logit é derivado de uma função de distribuição acumulada logística. A função do modelo logit é dada por:

$$
\operatorname{Prob}\left(y_{i}=1\right)=F\left(X_{i}^{\prime} \beta\right)=L\left(X_{i}^{\prime} \beta\right)=\frac{1}{1+e^{-X_{i}^{\prime} \beta}}
$$

onde: nessa função a probabilidade assume valores entre o e 1 quando $-X_{\mathrm{i}} \beta$ varia de $-\infty$ a $+\infty$, respectivamente. Da mesma forma, divide-se a probabilidade de sucesso, a equação (4), pela probabilidade de não-sucesso, $\frac{1}{1+e^{X_{i}^{\prime} \beta}}$, obtendo-se a razão de probabilidades,

$$
\frac{\operatorname{Prob}\left(y_{i}=1\right)}{1-\operatorname{Prob}\left(y_{i}=1\right)}=e^{X_{i}^{\prime} \beta}
$$

Também se encontra exposto de forma mais extensa a definição da função de máxima-verossimilhança utilizada para estimar os parâmetros que maximizam a probabilidade de uma determinada amostra pertencer a uma população, onde, como visto, para a forma funcional de um modelo de resposta binária, como o logit, temse que:

$$
L=\prod_{i=1}\left[F\left(X_{i}^{\prime} \beta\right)\right]^{y i}\left[1-F\left(X_{i}^{\prime} \beta\right)\right]^{1-y i}
$$

O modelo de regressão com efeito threshold pode ser expresso por ${ }^{8}$ :

$$
\begin{aligned}
& y_{i}=\theta_{1}^{\prime} x_{i}+\varepsilon_{i}, \quad q_{i} \leq \gamma \\
& y_{i}=\theta_{2}^{\prime} x_{i}+\varepsilon_{i}, \quad q_{i}>\gamma
\end{aligned}
$$

\footnotetext{
${ }^{8}$ Para maiores informações, ver McFadden (1974).
} 
Em que o modelo com uma única equação é expresso por:

$$
y_{i}=\theta_{2}^{\prime} x_{i}+\delta_{n}^{\prime} x_{i}(\gamma)+\varepsilon_{i}
$$

Ou, de forma matricial,

$$
Y=X \theta+X_{n} \delta_{n}+\varepsilon
$$

Além disso, também é proposto um modelo de seleção amostral, por dois estágios, para inclusão da variável inversa de Mills na equação principal de segundo estágio. A importância da razão inversa de Mills é tornar possível a correção do viés de seleção quando uma equação de seleção é identificada. A inclusão da razão inversa de Mills na equação principal leva em conta explicitamente a decisão do prefeito reelegível na sua escolha entre se reeleger ou não, de forma que esse termo elimina o viés de seletividade e consequentemente nos dá estimativas consistentes dos parâmetros da equação principal.

\subsection{0 modelo proposto e discussão da direção das variáveis}

Inicialmente, em primeiro estágio, estima-se o modelo de seleção amostral, composto por toda amostra de 4.561 prefeitos eleitos em 2004 e reelegíveis para 2008, porém com apenas 2.845 decisões de candidaturas à reeleição. O modelo é descrito a seguir:

$$
{\text { Cand } 08_{i}}=\delta_{0}+\delta_{1} P P 04+\vartheta_{i}
$$

A variável Cando8 assume valor 1 se o prefeito de 2004 reelegível para 2008 decide se candidatar à reeleição e, assume zero caso contrário. A variável $\mathrm{PPo}_{4}$ significa que o prefeito pertence à coligação do presidente eleito em 2006 (PT, PCdoB e PRB), considerando neste momento sua legenda de 2004. O fato de participar da coligação do presidente, na época com alta popularidade, pode influenciar a decisão do prefeito por optar pela reeleição. O modelo é estimado através da função logística.

Posteriormente, estima-se o impacto sobre a reeleição de 2008, em segundo estágio. Para descrever o impacto das variáveis gastos em campanhas, o incumbente pertencer à coligação do partido do Governador e do Presidente, aqui descritos pela sua legenda de 2008 , e, principalmente, a qualidade das escolas municipais e quantidade de atendimentos (controlada pelo tamanho da população do município), controladas por um efeito limiar de renda per capita dos municípios, 
sobre o sucesso eleitoral na eleição de prefeito em 2008 no Brasil, foi utilizada a seguinte regressão, sobre os 2845 candidatos à reeleição em 2008:

$$
\operatorname{SUCESSO}_{i}=\frac{1}{1+e^{-(z)}}
$$

onde:

$$
\begin{gathered}
(z)=\left\{\alpha_{1}+\alpha_{2} \text { GASTCAMP }_{i}+\alpha_{3} I D E B_{i}+\alpha_{4}(\text { SAUDE } / P O P)_{i}+\alpha_{5} P G_{i}+\right. \\
\left.\alpha_{6} \text { PP }_{i}\right\} I(\text { RENDACAPITA } \leq \gamma)+\left\{\beta_{1}+\beta_{2} \text { GASTCAMP }_{i}+\beta_{3} I D E B_{i}+\beta_{4}(\text { SAUDE } / P O P)_{i}+\right. \\
\left.\beta_{5} P G_{i}+\beta_{6} P_{i}\right\} I(\text { RENDACAPITA }>\gamma)
\end{gathered}
$$

Quadro 1 - Variáveis do modelo e sinal esperado

\begin{tabular}{|l|l|l|}
\hline \hline Variável & Sinal esperado & Com efeito Threshold \\
\hline GASTCAMP & $\alpha_{2}>$ o e $\beta_{2}>0$ & $\alpha_{2}>\beta_{2}$ \\
\hline IDEB & $\alpha_{3}>$ o e $\beta_{3}>0$ & $\alpha_{3}<\beta_{3}$ \\
\hline SAUDE/POP & $\alpha_{4}>$ o e $\beta_{4}>0$ & $\alpha_{4}>\beta_{4}$ \\
\hline PGo8 & $\alpha_{5}>$ o e $\beta_{5}>0$ & $\alpha_{5}>\beta_{5}$ \\
\hline PPo8 & $\alpha_{6}>$ o e $\beta_{6}>0$ & $\alpha_{6}>\beta_{6}$ \\
\hline \hline
\end{tabular}

Fonte: Elaborado pelos autores.

O efeito limiar que minimiza a soma dos quadrados dos resíduos é a renda per capita de $\mathrm{R} \$$ 3.170,0o. Ou seja, a dinâmica de sucesso eleitoral é diferente para rendas per capita acima e abaixo deste efeito limiar.

A expectativa de que os parâmetros $\alpha_{2}>0$ e $\beta_{2}>0$ tenham essa direção está associada ao fato de que quanto maior o investimento na campanha eleitoral, maior a probabilidade de sucesso. A expectativa de que $\alpha_{2}>\beta_{2}$, que mostraria que o impacto desse investimento em campanha é maior para municípios com menor renda per capita, seria explicada pelo fato dessas localidades apresentarem menor quantidade de eleitores ideológicos (ou seja, mais informados). Portanto, o impacto do gasto em campanha, que fornece mais informação ao eleitorado devido à exposição do candidato, seria maior nessas localidades.

Ao mesmo tempo, a direção de $\alpha_{3}>$ o e $\beta_{3}>$ o indicaria um impacto positivo da nota do IDEB das escolas municipais sobre o sucesso eleitoral. Como é um serviço público de grande importância, entende-se que a população observa a qualidade das escolas, i.e., a qualidade da educação no município sob a gestão do prefeito. No entanto, em municípios de renda mais elevada, como pressuposto anteriormente, figuram mais eleitores bem-informados. Considerando a divulgação das notas do IDEB poucos meses antes das eleições de 2008, uma importância maior seria dada 
por esses eleitores no momento de reeleger o gestor ao cargo. Logo, espera-se que $\beta_{3}$ $>\alpha_{3}$.

Os parâmetros $\alpha_{4}>$ o e $\beta_{4}>$ o relacionam a quantidade de atendimentos na área de saúde, relativa ao tamanho da população do município, com o sucesso eleitoral do incumbente. Novamente, sendo um serviço público fundamental para a população, supõe-se que o atendimento ambulatorial seja uma medida correta de qualidade do serviço, e algo considerado no momento de votar. No entanto, em municípios de renda mais baixa, espera-se que a procura pelo sistema de saúde público seja maior, tanto pela renda inferior da população local, como pela oferta reduzida de hospitais e clínicas particulares. Logo, $\alpha_{4}>\beta_{4}$ implica maior impacto da variável Saúde nesses municípios de renda per capita mais baixa, quando comparado ao impacto nos municípios de renda mais elevada.

Os sinais de $\alpha_{5}>$ o e $\beta_{5}>$ o relacionam o fato do prefeito atual que concorre à reeleição pertencer a um partido que faz parte da coligação do Governador do Estado aumentaria as chances de eleição do incumbente. A justificativa para $\alpha_{5}>\beta_{5}$ é a seguinte: uma quantidade maior de eleitores ideológicos ${ }^{9}$ e bem-informados estaria presente nos municípios de renda mais elevada, supostamente mais desenvolvidos. Em municípios abaixo do efeito limiar, o apoio do governador sugere confiança por parte da administração, conferindo maior legitimidade à candidatura.

Finalmente, $\alpha_{6}$ e $\beta_{6}$ estão relacionados ao fato do prefeito ser do Partido do Presidente da República ou fazer parte de uma coligação deste, no qual o impacto disso seria positivo não apenas pela exposição maior do candidato, mas pela popularidade do Presidente da República à época. $\alpha_{6}>\beta_{6}$ justifica-se pela mesma forma que anteriormente, uma quantidade menor de eleitores ideológicos manteria o prefeito no cargo por suas relações com governantes de outras esferas.

\section{Resultados}

A Tabela 6 a seguir apresenta os resultados obtidos no modelo que minimiza a soma dos quadrados dos resíduos. Nesse modelo, nem todas as variáveis respondem conforme o esperado.

Como pode ser observado pela Tabela 6, existe uma relação positiva e significante entre o sucesso eleitoral do incumbente e os seus gastos em campanha para os municípios de renda per capita abaixo do efeito limiar.

\footnotetext{
9 A discussão a respeito de eleitores ideológicos advém do trabalho de Persson e Tabellini, "Political Economics" (2000).
} 


\section{Tabela 6: Estimação do Modelo de Sucesso Eleitoral de Candidatos Concorrendo à Reeleição com Efeito Threshold}

\begin{tabular}{|c|c|c|c|c|}
\hline Variável & Coeficiente & Erro Padrão & $\begin{array}{c}\text { Estatística } \\
\mathrm{Z}\end{array}$ & P-valor \\
\hline $\begin{array}{l}\text { MODELO PRINCIPAL VARIÁVEL } \\
\text { DEPENDENTE SUCESSO }(\mathrm{N}=\mathbf{2 8 4 5})\end{array}$ & \multirow[b]{2}{*}{0.447103} & \multirow[b]{2}{*}{0.221247} & \multirow[b]{2}{*}{2.020832} & \multirow[b]{2}{*}{0.0433} \\
\hline CONSTANTE & & & & \\
\hline GASTCAMP $*($ RENDA $<=3.170,00)$ & $1.83 \mathrm{E}-06$ & $8.40 \mathrm{E}-\mathrm{O} 7$ & 2.183584 & 0.0290 \\
\hline GASTCAMP * $($ RENDA >3.170,0o $)$ & $4.86 \mathrm{E}-07$ & $2.12 \mathrm{E}-\mathrm{O} 7$ & 2.294635 & 0.0218 \\
\hline IDEB $^{*}($ RENDA $<=3.170,00)$ & -0.025867 & 0.073264 & -0.353063 & 0.7240 \\
\hline $\mathrm{IDEB}^{*}(\mathrm{RENDA}>3.170,00)$ & 0.096575 & 0.049168 & 1.964172 & 0.0495 \\
\hline$(\mathrm{SAUDE} / \mathrm{POP}) *(\mathrm{RENDA}<=3.170,00)$ & 0.718631 & 0.213036 & 3.373289 & 0.0007 \\
\hline$(\mathrm{SAUDE} / \mathrm{POP}) *(\mathrm{RENDA}>3.170,00)$ & 0.065124 & 0.091028 & 0.715427 & 0.4743 \\
\hline PGo8* $($ RENDA $<=3.170,00)$ & 0.126106 & 0.136262 & 0.925469 & 0.3547 \\
\hline PGo8* $($ RENDA $>3.170,00)$ & 0.102990 & 0.117988 & 0.872882 & 0.3827 \\
\hline PPo8* $($ RENDA $<=3.170,00)$ & 0.195120 & $0.24055^{2}$ & 0.811134 & 0.4173 \\
\hline PPo8* $($ RENDA $>3.170,00)$ & 0.152310 & 0.200502 & 0.759641 & 0.4475 \\
\hline MILLS*(RENDACAPITA<=3.17) & -0.221147 & 0.187978 & -1.176450 & 0.2394 \\
\hline MILLS* $($ RENDACAPITA>3.17) & -0.271099 & 0.143997 & -1.882664 & 0.0597 \\
\hline $\begin{array}{l}\text { MODELO DE SELEÇÃO - } \\
\text { VARIÁVEL DEPENDENTE } \\
\text { CANDo8 }(\mathrm{N}=4561)\end{array}$ & \multirow[b]{2}{*}{0.408059} & \multirow[b]{2}{*}{0.032881} & \multirow[b]{2}{*}{12.41036} & \multirow[b]{2}{*}{0.0000} \\
\hline CONSTANTE & & & & \\
\hline PPo4 & 0.429127 & 0.088366 & 4.856273 & 0.0000 \\
\hline
\end{tabular}

Fonte: Elaboração dos autores.

No entanto, para municípios de renda mais elevada, a variável gastos em campanha não tem significância. Isso implica que a população de municípios de renda per capita mais elevada, por suposto de maior educação e com quantidade mais elevada de eleitores ideológicos, não considera tal variável relevante. A suposição, assim, é que sua performance no provimento de bens públicos seria mais importante para esse grupo de eleitores.

A esse respeito, as variáveis IDEB e Saúde, respectivamente analisando a qualidade do sistema de educação municipal e do sistema de saúde público, ambos geridos pela administração local, apresentam resultados interessantes. De maneira intuitiva, o IDEB é observado pelos eleitores dos municípios de renda per capita mais elevada como algo relevante, sua relação com o sucesso eleitoral sendo significante e positiva. 
Ou seja, uma gestão considerada positiva na educação aumenta as chances de reeleição do governante. Isso está de acordo com o trabalho de Firpo et al. (2012), que apresenta resultados em que um aumento na nota do IDEB aumenta a chance de eleição do governante. No entanto, o mesmo não é observado em municípios de renda per capita mais baixa. $O$ resultado não é surpreendente, pois em tais municípios a quantidade de eleitores bem informados seria menor. Ainda que seja dada importância à qualidade da educação, possivelmente esses eleitores não associaram os resultados obtidos pelas escolas diretamente à administração pública, talvez focando em outras variáveis, como a quantidade de vagas disponíveis.

Esse resultado não está de acordo com o trabalho supracitado de Firpo et al. (2012), cujo impacto, no artigo dos autores, dado ao IDEB no sucesso eleitoral, mostra-se ainda mais relevante em municípios de renda menor. No entanto, não há incongruência, pois os dois trabalhos utilizam variáveis diferentes, onde Firpo et al. (2012) trabalha com variações no IDEB, ao contrário do presente trabalho, que utiliza as médias para o período 2005 a 2007 , divulgadas pouco antes das eleições em outubro de 2008.

Já no caso da saúde, são nesses municípios de menor renda em que aumenta a probabilidade de reeleição do prefeito. Quanto maior a quantidade de atendimentos no sistema público de saúde, maiores as chances de o prefeito ser reconduzido ao cargo. $\mathrm{O}$ mesmo não ocorre para municípios de renda mais alta, o que pode estar ligado ao fato de que nessas localidades há uma maior oferta do sistema privado de saúde, e uma população mais abastada busca essa fonte de cuidado de forma mais frequente, devido à suposta maior qualidade e rapidez do atendimento. No entanto, deve-se ressaltar que municípios maiores com frequência são referências de serviços de maior complexidade para localidades menores. Assim, a população atendida não necessariamente é a votante daquela localidade.

Todavia, o resultado para municípios de renda abaixo do efeito limiar está de acordo com aquele encontrado em Novaes e Mattos (2010), que relaciona tentativa de aumentar as chances de sucesso eleitoral com maiores gastos na área de saúde por parte dos governantes.

Mais interessante é a falta de significância das variáveis Partido do Governador e Partido do Presidente. Ao contrário do que poderia ser esperado, a população, tanto de municípios de renda mais elevada, quanto de renda mais baixa, aparenta não considerar como relevante as relações entre os governantes das diferentes esferas. Por um lado, esse resultado dá força à hipótese de que, uma vez no poder, os eleitores consideram mais relevante a performance do governante no cargo, e não sua filiação partidária.

Para um país como o Brasil, e considerando que nas eleições de 2008 a verticalização entre partidos já não se fazia presente, tal conclusão é compreensível, e tal resultado está coerente com aquele apresentado em Mendes e Rocha (2004), 
que também não encontram relação entre apoio do governador e reeleição para o caso mineiro. No entanto, outro aspecto a ser considerado, especificamente com relação à variável Partido do Presidente, é que o Presidente da República em 2008, Luiz Inácio Lula da Silva, carregava considerável popularidade ${ }^{10}$, e por conta disso, como reforçaram diversos cientistas políticos naquele contexto, muitos candidatos utilizaram de sua imagem, mesmo sem fazer parte de coligação partidária comum, e independentemente de autorização ${ }^{11}$.

Pode-se sumarizar, então, que os resultados encontrados estão, em média, próximos daqueles encontrados nos demais trabalhos da literatura que abordam o tema eleitoral. Cabe, naturalmente, observar de forma crítica as indicações do modelo logit. Algumas variáveis podem ser ainda mais apropriadas para capturar a intenção de voto. Assim como a utilização da quantidade de atendimento no sistema de saúde, poderia ser adequada a utilização da quantidade de vagas nas escolas, como proxy da atuação do prefeito no sistema educacional. Ou, ainda, a quantidade de escolas construídas, algo mais imediatamente atrelado ao prefeito no cargo, dado que melhorias no IDEB podem ser consideradas como evoluções que ocorrem devido às políticas de Estado, a longo prazo, que ultrapassam mandatos de determinados políticos. A consideração cuidadosa de inclusão ou substituição de variáveis no modelo certamente merece atenção em futuras extensões da presenta pesquisa.

\section{Conclusão}

Este trabalho teve como proposta analisar, no contexto das eleições municipais para prefeito de 2008 no Brasil, a percepção do eleitorado com relação a índices de educação e saúde, especificamente as notas do IDEB e a quantidade de atendimentos ambulatoriais, e se essas variáveis são determinantes para o sucesso eleitoral do prefeito no cargo que busca a reeleição.

Diversos trabalhos, como os de Erikson e Wright (2001) e Abramowitz et al. (2006), no âmbito internacional, e Dos Santos (2012), têm discutido como políticos já no poder têm vantagens sobre seus desafiantes. No entanto, como aponta Trounstine (2009, 2001), o grau dessa vantagem, e porque motivo esta acontece, ainda são debatidos com frequência no meio acadêmico.

\footnotetext{
${ }^{10}$ Ver, por exemplo: http://revistaepoca.globo.com/Revista/Epoca/o,EDG83371-6oo9-519,ooPOPULARIDADE+DE+LULA+E+RECORDE+E+MAIORIA+DEFENDE+TERCEIRO+MANDATO+APO NTA+PE.html e http://www1.folha.uol.com.br/folha/brasil/ult96u439697.shtml. Acesso: 10/o4/2019. ${ }^{11}$ Ver, por exemplo:

http://eleicoes.uol.com.br/2008/ultnot/multi/2008/10/o5/0402396CD8A91326.jhtm?popularidade-delula-e-usada-por-aliados-e-pela-oposicao-0402396CD8A91326 Acesso: 10/04/2019.
} 
Num modelo logit, em que a variável dependente é o sucesso eleitoral do candidato incumbente, e o efeito limiar é determinado pela variável renda per capita dos municípios, são incluídas variáveis para serviços públicos essenciais para a população; a educação e a saúde.

Para a educação foram utilizados os resultados do IDEB, índice que é calculado com base na taxa de rendimento escolar (aprovação e reprovação) e no desempenho dos alunos no SAEB (Sistema Nacional de Avaliação da Educação Básica) e na Prova Brasil. Sua fonte é o Instituto Nacional de Estudos e Pesquisas Educacionais Anísio Teixeira (INEP). Para a saúde, os dados utilizados, com fonte no DataSUS, são os atendimentos ambulatoriais, ou seja, todos aqueles atendimentos em uma unidade de saúde pública onde não ocorre necessariamente a internação. Para que não seja observada apenas a quantidade total de atendimentos no município, leva-se em consideração a proporcionalidade, sendo esse índice dividido pela população da localidade.

Além dessas duas variáveis, são utilizados os dados de gasto em campanha por parte dos candidatos, visando medir a influência do poder econômico e exposição do candidato na eleição, assim como uma variável dummy que identifica que o partido do prefeito que busca a reeleição faz parte (ou não) da coligação do Governador do Estado a que pertence o seu município e a coligação do partido do Presidente da República.

Primeiramente, os resultados apresentam uma relação positiva e significante entre o gasto em campanha e sucesso eleitoral. No entanto, isso é observado apenas para municípios de renda per capita inferior ao efeito limiar (threshold); para municípios de renda mais elevada, a variável não é significante. Isso sugere que em municípios de eleitores menos informados, o poder econômico do candidato ainda o faz levar vantagem sobre os demais. Mas, note-se que em municípios com quantidade maior de eleitores ideológicos (mais informados), ou seja, os municípios de maior renda per capita, tal importância desaparece, em que, possivelmente, o foco é apenas na performance no cargo executivo.

Em relação a esse aspecto, as variáveis que medem a qualidade da educação e a quantidade de atendimentos da saúde apresentam os resultados esperados. Contudo, há disparidade entre os diferentes tipos de municípios, de acordo com sua renda. Em municípios de renda mais elevada, ou acima do efeito limiar, apenas a qualidade da educação é observada. Isso pode ser explicado partindo do pressuposto de que nesses municípios há quantidade maior de eleitores bem informados e ideológicos, uma importância e atenção maior seria dada a dados sobre educação. Possivelmente o fornecimento de vagas para os estudantes seria o suficiente para satisfazer eleitores menos informados, ainda não cientes da importância, também, da qualidade do ensino, e não apenas o seu fornecimento. Cabe, em trabalho futuro, 
buscar a inclusão de uma variável que mensure a quantidade de escolas ou vagas no sistema público municipal.

Já para os municípios de renda mais baixa, apenas a variável saúde é observada como relevante, algo que não ocorre para os municípios de renda mais elevada. Enquanto a demanda em municípios de renda mais baixa seria quase que exclusivamente direcionada ao sistema público de saúde, o que faz com que o resultado seja o esperado, o fato desse resultado não ser significante em municípios de renda mais elevada pode ser explicado pelo fato de, primeiro, a oferta do setor privado ser consideravelmente mais extensa e, também, pelo maior poder aquisitivo da população, o atendimento seja direcionado de forma contundente a esse setor. Esse resultado parece corroborar os achados de Novaes e Mattos (2010), que apresentam um aumento nos gastos de saúde por parte de prefeitos que buscam a reeleição, ou que pretendem facilitar a eleição de um colega de partido como seu sucessor.

Esses resultados, de uma forma geral, condizem com aqueles encontrados em Berry e Howell (2007), em que os eleitores de fato consideram a administração de um governante como fator preponderante no momento da eleição.

Finalmente, os resultados das variáveis Partido do Governador e Partido do Presidente trazem uma novidade importante. Uma vez que o candidato já esteja no poder, os eleitores de nenhum dos dois tipos de municípios consideram relevante, ao contrário de anteriormente, o fato do prefeito estar ligado, através de coligação partidária, ao Governador do Estado ou ao Presidente da República. Isso concorda com a avaliação de que o desempenho do prefeito passa a ser o fator primordial na eleição, e não sua ligação política. Tal resultado está de acordo com aquele apresentado por Mendes e Rocha (2004), em sua análise para os municípios mineiros.

Tendo em vista os resultados apresentados por este trabalho, há indícios de que políticas públicas voltadas para a educação e saúde não apenas beneficiam a população, mas também podem ser benéficas para aumentar a probabilidade de eleição de um gestor. Claramente, ainda que dependa do contexto, o eleitorado observa o desempenho do governante e avalia a sua performance para reconduzi-lo ao cargo.

Uma extensão do trabalho a ser realizada futuramente consiste em atualizar a base de dados para incluir as eleições municipais de 2012 e 2016. Além disso, uma avaliação criteriosa de quais variáveis poderiam ser acrescidas para refletir de forma ainda mais acurada a percepção do eleitor do executivo e avaliar se os resultados são mantidos, tanto com os dados de mais pleitos quanto com essas novas variáveis. 


\section{Referências}

ABRAMOWITZ, A.; ALEXANDER, B.; GUNNING, M. Don't Blame Redistricting for Uncompetitive Elections. PS: Political Science and Politics, v. 39, n. 1, p. 87-90, 2006. DOI: https://doi.org/10.1017/S1049096506060185

BAER, W.; KERSTENETZKY, I.; VILLELA, A. V. As Modificações no Papel do Estado na Economia Brasileira. Pesquisa e Planejamento Econômico. Rio de Janeiro. V. 3, n. 4: p. 883-912. Dez 1973.

http://repositorio.ipea.gov.br/handle/11058/6554

BENEVIDES, C.V. Um Estado de Bem-Estar Social no Brasil? Dissertação de Mestrado. Universidade Federal Fluminense. Fevereiro 2011.

BERRY, C. R.; HOWELL, W. G. Accountability and local elections: rethinking retrospective voting. The Journal of Politics, v. 69, n. 3, p. 844-858, Ago., 2007. DOI: https://doi.org/10.1111/j.1468-2508.2007.00579.X

CANÇADO, P. L.; JUNIOR, A. F. de A. Economics and politics: o que determina as chances de reeleição em municípios? O caso das eleições municipais de Minas Gerais - 2000. Working Paper, Ibmec MG, WP26, 2004.

SENA, P. de. O município e a responsabilidade pela educação infantil na Constituição, na LDB e no PNE. Consultoria Legislativa: Estudo. Câmara dos Deputados. Julho, 2004.

SANTOS, S. A. dos. Eleições municipais 2012: possibilidades de reeleição e sucessão nas capitais brasileiras. Em Debate, Opinião Pública e Conjuntura Política, UFMG, Ano 4, Abril, 2012.

ERIKSON, R. S.; WRIGHT, G. Voters, issues and candidates in congressional elections. In: DODD, L.; OPPENHEIMER, B. Congress Reconsidered. 7. ed. Washington D.C.: CQ Press, 2001.

FEREJOHN, J. Incumbent performance and electoral control. Public Choice, v. 50, n. 1-3, p. 5-25, 1986. https://doi.org/10.1007/BFoo124924

FERNANDES, R; GREMAUD, A. P. Qualidade da Educação: Avaliação, Indicadores e Metas. In: VELOSO, Fernando; PESSÔA, Samuel; HENRIQUES, Ricardo; GIAMBIAGI, Fábio. (Org.). Educação básica no Brasil: Construindo o País do Futuro. Rio de Janeiro: Elsevier, v. 1, p. 213-238, 2009.

FIRPO, S; PIERI, R. de; SOUZA, A. P. Electoral impacts of uncovering public school quality: evidence from Brazilian municipalities. IZA Discussion Papers 6524, Institute for the Study of Labor (IZA), 2012. DOI: http://dx.doi.org/10.1016/j.econ.2016.07.003 
GOMES, F. M. R. Responsabilidade do Estado por Ineficiência na Prestação de Serviços de Saúde Pública. Revista Argumenta, N. 12. 2010. DOI: http://dx.doi.org/10.35356/argumenta.v12i12.165

GUJARATI, D. N. Econometria Básica. São Paulo: Makron Books, 2000. HANUSHEK, E. A. The Economics of School Quality. German Economic Review, v. 6, n. 3, p. 269-286, 2005. https://doi.org/10.1111/j.1468-0475.2005.00132.x KLEIN, F. A. Reelection incentives and political budget cycle: evidence from Brazil. Revista de Administração Pública, FGV, v. 44, n. 2, p. 283-337, mar./abr., 2010. http://dx.doi.org/10.1590/Soo34-76122010000200006

KRUEGER, A. B.; LINDAHL, M. Education for growth: Why and for whom? Journal of Economic Literature, v. 39, p. 1101-1136, dez., 2001. DOI: 10.3386/w7591 LAZEAR, E. P. Teacher incentives. Economic Policy Review, Swedish, v. 10, p. 179-214, 2003.

. Educational production. Quaterly Journal of Economics, v. 116, p. 777803, 2001. https://doi.org/10.1162/00335530152466232 . Performance pay and productivity. American Economic Review, v. 90, n. 5, p. 1346-1362, Dec., 2000. DOI: 10.1257/aer.90.5.1346 LIMA, R. C. Modelos de respostas binárias: especificação, estimação e inferência. Agricultura em São Paulo, 1996.

MCFADDEN, D. L. Conditional logit analysis of qualitative choice behavior. In: ZAREMBKA, P. (ed.). Frontiers in Econometrics. New York: Academic Press, 1974. P. 105-142.

MELONI, L. E. N. Os efeitos das expectativas de reeleição sobre os ciclos políticos: uma análise empírica a partir da política fiscal dos municípios brasileiros. 2011. Dissertação (Mestrado) - Universidade de São Paulo, 2011. MENDES, M. Desigualdade e Crescimento: Uma Revisão da Literatura. IPEA: Textos para Discussão, N. 131. 2013

MENDES, M.; ROCHA, C. A. A. O que reelege um prefeito? Textos para Discussão, Consultoria Legislativa do Senado, n. 7, Abril, 2004.

MULLIGAN, C. B. Galton vs the human capital approach to inheritance. Journal of Political Economy, v. 107, p. 184-224, 1999.

NOVAES, L.; MATTOS, E. O efeito da intenção de reeleição sobre gastos em saúde: Uma análise com base no modelo de reputação política. Revista de Economia Política, v. 30, n. 1, 2010. http://dx.doi.org/10.1590/So101-31572010000100009 PERSSON, T.; ROLAND, G.; TABELLINI, G. Separation of powers and political accountability. The Quarterly Journal of Economics, MIT Press, v. 112, n. 4, p. 
1163-1202, November, 1997.

PERSSON, T.; TABELLINI, G. Political Economics. MIT Press. 2000.

SAES, S. G. Estudo bibliométrico das publicações em economia da saúde no Brasil, 1989-1998. Dissertação (Mestrado em Administração de Serviços de Saúde) - Faculdade de Saúde Pública, Universidade de São Paulo, SãoPaulo, 200o. DOI: http://dx.doi.org/10.11606/D.6.200o.tde-01032002-132854

SAKURAI, S. N.; MENEZES FILHO, N. A. Fiscal policy and reelection in brazilian municipalities. Public Choice, v. 137, p. 301-314, 2008. DOI:

https://doi.org/10.1007/s11127-008-9329-3

SAKURAI, S. N.; MENEZES FILHO, N. A. Opportunistic and partisan election cycles in Brazil: new evidence at the municipal level. Public Choice, v. 148, p. 233247, 2011. DOI: http://dx.doi.org/10.1007/s11127-010-9654-1

PORTO, S. M.; UGÁ, M. A. D.; MOREIRA, R. da S. Uma Análise da Utilização de Serviços de Saúde por Sistema de Financiamento: Brasil 1998-2008. Ciência Saúde Coletiva[online]. 2011, vol. 16, n. 9, p. 3795-3806. ISSN 1413-8123. DOI:

http://dx.doi.org/10.1590/S1413-81232011001000015

SEN, A. A Ideia de Justiça. Companhia das Letras. 2011

Desenvolvimento como Liberdade. Companhia das Letras. 2000

TOPEL, R. Labor markets and economic growth. In: ASHENFELTER, O.; CARD, D. (ed.). Handbook of labor economics, 1. ed. 1, v. 3, Elsevier, 1999. Cap. 44, p. 29432984 .

TROUNSTINE, J. Evidence of a local incumbency advantage. Legislative Studies Quarterly, v. 36, n. 2, May, 2011. DOI: https://doi.org/10.1111/j.19399162.2011.00013.X

. Information, Turnout, and Incumbency in Local Elections. University of California-Merced mimeo, 2009.

VIDEIRA, R. A.; MATTOS, E. Ciclos Políticos Eleitorais e a Interação Espacial de Políticas Fiscais entre os Municípios Brasileiros. Economia Aplicada, v. 15, n. 2, Ribeirão Preto, Apr. /June 2011.

WITTMAN, D. Why democracies produce efficient results. Journal of Political Economy, v. 97, n. 6, p. 1395-1424, 1989. DOI: http://dx.doi.org/10.1086/26166o 